\title{
In-situ synthesis of $\mathrm{CaO}$ and $\mathrm{SiO}_{2}$ nanoparticles onto jute fabrics: exploring the multifunctionality
}

\author{
Joana C. Araújo · Diana P. Ferreira (D) Pilar Teixeira · Raul Fangueiro
}

Received: 28 April 2020/Accepted: 29 October 2020/Published online: 9 November 2020

(C) Springer Nature B.V. 2020

\begin{abstract}
Fibrous based materials with exceptional functionalities have become a target of interest for researchers worldwide. One promising strategy for the development of active fibrous structures with improved functions is their functionalization with nanoparticles (NPs). In this work, jute fabrics were functionalized with calcium oxide $(\mathrm{CaO})$ and silica $\left(\mathrm{SiO}_{2}\right)$ NPs in order to obtain fibrous structures with several properties including, hydrophobicity, UV protection, antibacterial activity and the degradation of dyes ability. $\mathrm{CaO}$ and $\mathrm{SiO}_{2}$ NPs were synthesized via a simple in situ method, using sodium hydroxide $(\mathrm{NaOH})$ as the reducing agent and water as solvent. Parallelly, the in situ synthesis of the $\mathrm{CaO}$ NPs was also tested. The final systems were fully characterized using Attenuated Total Reflectance-Fourier Transform Infrared Spectroscopy, Ground-State Diffuse Reflectance and Field Emission Scanning Electron Microscopy and Energy Dispersive Spectroscopy. All
\end{abstract}

J. C. Araújo - D. P. Ferreira $(\bowtie) \cdot$ R. Fangueiro Centre for Textile Science and Technology (2C2T), University of Minho, 4800 Guimarães, Portugal e-mail: diana.ferreira@det.uminho.pt

P. Teixeira

CEB - Centre of Biological Engineering, University of Minho, 4710-057 Braga, Portugal

R. Fangueiro

Department of Mechanical Engineering, University of

Minho, Guimarães, Portugal these techniques confirmed the successful synthesis of the NPs as well as their well distributed presence onto the fabrics. The samples exhibited very good contact angle values, reaching $143.7^{\circ}$ for the fabrics functionalized with $\mathrm{CaO}$ and $\mathrm{SiO}_{2}$ NPs and great values of ultraviolet (UV) protection factors (UPF), reaching $50+$ for the functionalized fabrics. The developed systems also exhibited antibacterial activity against Staphylococcus aureus and Escherichia coli and photocatalytic activity for the degradation of methylene blue. The wash durability of the nanocoating was also evaluated, confirming that the $\mathrm{SiO}_{2}$ improved the NPs' anchorage onto the fabrics. Overall, this work presents for the first time, the development of jute fabrics with $\mathrm{CaO}-\mathrm{SiO}_{2}$ NPs with several functionalities.

Keywords Jute fibers · In situ-synthesis . Nanoparticles - Antibacterial activity · Hydrophobicity $\cdot$ Photodegradation

\section{Introduction}

The development of multifunctional fibrous based materials has become a target of interest for many researchers all over the world. Nanotechnology could be responsible for the enhancement of textiles properties, since the incorporation of nanomaterials can 
introduce several functionalities, that can include, easy/self-cleaning, decomposition of chemical agents, antimicrobial activity, flame retardancy, UV-protection, antistatic properties and monitoring/sensing behavior (Costa et al. 2018; Joshi and Adak 2018; P Ferreira et al. 2018). The functionalization of fibers with NPs is an eminent alternative in the development of functional fibrous systems.

One of the biggest concerns for governments worldwide has been the protection against emerging infectious diseases. Antibacterial textile substrates prevent the growth, or even kill microorganisms, reducing the transmission of these diseases (Qiu et al. 2020). Thus, the functionalization of fibers in order to obtain antibacterial activity is essential. Hydrophobic textiles have also attracted some attention due to their capacity for liquid repellency, self-cleaning and unidirectional fluid transport, which can turn these materials into great alternatives to be used for several applications (Tissera et al. 2015).

The excessive unprotected solar exposure can lead to several health issues, mostly skin damage, like aging, acne and even melanoma and carcinoma. An effective UV protection material, that prevents the harmful effects caused by the sun, is of huge importance (Sasani Ghamsari et al. 2017).

The disposal of several noxious pollutants without a proper treatment has been perpetually increasing. This is one of the biggest causes of environmental pollution. Therefore, there is the need to develop various methods for the removal of these pollutants. One of the methods with this finality that has been showing the greatest potential is photocatalysis, especially for the removal of organic pollutants. Semiconductors have been reported as one of the best materials for photocatalysis, since they are able to degrade organic compounds using irradiation of light with different wavelengths (Nagpal and Kakkar 2019).

Dyes are considered the most common industrial pollutant and their concentrations can be easily monitored by a UV-Vis spectrometer, which makes them one of the most used compounds on photocatalytic degradation tests. $\mathrm{MB}$ is a poisonous dye that causes breathing hazards, vomiting and mental disorders (Balu et al. 2018). Due to the noxious effects that dyes have on humans, the development of catalytically active fabrics, with self-decontaminating properties, present great potential for application in chemical protective clothing against several harmful chemicals (Boufi et al. 2019).

NPs present great potential for imparting various functionalities to textiles due to their nanoscale dimension and very high surface area to volume ratio (Mary Ealias and Saravanakumar 2017). One type of NPs that has obtained considerable research attention is metal oxide NPs, due to their exceptional electrical, optical, magnetic and catalytic properties (Chavali and Nikolova 2019). This excellent set of characteristics have allowed their wide application in several areas, including agriculture, healthcare and industry (Nguyen et al. 2018).

Metal oxide NPs, namely: zinc oxide $(\mathrm{ZnO})$, titanium oxide $\left(\mathrm{TiO}_{2}\right), \mathrm{SiO}_{2}$, aluminum oxide $\left(\mathrm{Al}_{2} \mathrm{O}_{3}\right)$, magnesium oxide $(\mathrm{MgO})$ and cerium oxide $\left(\mathrm{CeO}_{2}\right)$ can be used for UV-protection purposes and decomposition of organic compounds, pesticides and microorganisms (Becheri et al. 2008; Duan et al. 2011). Within these particles, $\mathrm{CaO}$ NPs have shown a great potential as a cheap antibacterial agent, a photocatalyst for dye degradation and nanosized semiconductor. $\mathrm{CaO}$ NPs are excellent candidates for fibrous materials functionalization because when compared with other metal oxides, $\mathrm{CaO}$ is considered as a safe material to human beings, biocompatible, non-toxic and acceptable as food additive. It also has excellent antimicrobial potential, is adsorbent and in particular is known as a destructive adsorbent for toxic chemical agents. It is important to take all these described properties into account when thinking in textile applications since the developed materials could be in close contact with human skin (Bharathiraja et al. 2018). At the same time, $\mathrm{SiO}_{2} \mathrm{NPs}$ due to their easy and low-cost large-scale preparation, good biocompatibility and large specific area are widely used for several applications. One of the most important characteristics of $\mathrm{SiO}_{2}$ NPs is the possibility to merge with other materials, to combine their functionalities (Peerzada et al. 2019). The addition of $\mathrm{SiO}_{2}$ can improve the $\mathrm{CaO}$ NPs properties, due to its high active surface (Gunathilake and Jaroniec 2016).

Nowadays, with the environmental growing consciousness, there has been an increasing interest in the use of natural fibers instead of the synthetic ones, because of their biodegradability, biocompatibility, low-weight, high abundance and low-cost, which makes this kind of fibers an exceptional material for the development of an environmentally-friendly 
fibrous system (Costa et al. 2018). Jute is the second most produced fiber worldwide, after cotton. In addition to its great abundance in nature, jute is also cheap, biodegradable and has a low density. It also presents the possibility of being woven into different shapes and forms (Ivanovska et al. 2019; P Ferreira et al. 2018). These types of fibers also present very good mechanical properties, and the cellulose matrix of jute fabrics has already been reported has a great candidate for the dispersion of metal oxide NPs (Sahu et al. 2017). Jute also presents a lignin content of approximately $16 \%$, which is very high when compared to other bast fibers (del Río et al. 2009). In addition, can be easily manipulated and can be applied in several situations, especially for rapid environmental remediation (Hao et al. 2015).

Apart from the use of sustainable materials, like the natural fibers, it is also essential to reduce the environmental impact of the various industrial processes used for fibers' functionalization. In several research works, $\mathrm{CaO}$ NPs were synthesized using very high calcination temperatures, between 500 and $700{ }^{\circ} \mathrm{C}$ (Alavi and Morsali 2010; Anantharaman et al. 2016; Bharathiraja et al. 2018). Thus, avoiding the use of very high calcination temperatures is of major importance.

In this work, jute fabrics were functionalized with $\mathrm{CaO}$ and $\mathrm{SiO}_{2}$ NPs and several functionalities were studied. In a first stage, the pre-treated fabrics were functionalized with $\mathrm{CaO}$ and $\mathrm{SiO}_{2}$ NPs by a very simple in situ synthesis. The in situ synthesis of only the $\mathrm{CaO}$ NPs was also tested using as calcination temperature $150{ }^{\circ} \mathrm{C}$. All the developed fibrous systems were characterized by ATR-FTIR, GSDR and FESEM-EDS, that confirmed the successful synthesis of the two types of NPs. Functional properties of the samples were also evaluated, namely hydrophobicity by the contact angle measurement, UV protection behaviour, MB degradation and antibacterial tests against Staphylococcus aureus and Escherichia coli.

\section{Experimental}

\section{Materials}

The jute fabrics used in this work were produced using $100 \%$ natural jute yarns (Bangladesh origin) with weight of $430 \mathrm{~g} / \mathrm{m}^{2}$, supplied from RCS (Braga,
Portugal). Calcium nitrate tetrahydrate $\left(\mathrm{Ca}\left(\mathrm{NO}_{3}\right)_{2} \cdot 4-\right.$ $\mathrm{H}_{2} \mathrm{O}$ ) was purchase from Scharlau and $\mathrm{NaOH}$ from Normax Chem. Tetraethyl orthosilicate (TEOS) was obtained from Sigma-Aldrich. The ammonia $\left(\mathrm{NH}_{3}\right)$ was acquired from AnalaR NORMAPUR. The ethanol absolute used was purchased at José Manuel Gomes dos Santos. A Memmert UNE 800 oven was used. UV blacklight lamp $(15 \mathrm{~W})$ from $\mathrm{HQ}^{\mathrm{TM}}$ was used for photocatalytic tests.

\section{Fabrics pre-treatment}

Jute fabrics $(5 \mathrm{~cm} \times 5 \mathrm{~cm})$ were washed with $5 \%(\mathrm{v} /$ v) of non-ionic detergent at $80{ }^{\circ} \mathrm{C}$ for $30 \mathrm{~min}$ to remove the adhered impurities (waxes, fats, etc.). The fabrics were further cleaned in distilled water at $70{ }^{\circ} \mathrm{C}$ for $30 \mathrm{~min}$ and dried at $100{ }^{\circ} \mathrm{C}$ for $1 \mathrm{~h}$.

Functionalization of the fabrics with $\mathrm{CaO}$ and $\mathrm{SiO}_{2}$ nanoparticles

In-situ synthesis of $\mathrm{CaO}$ and $\mathrm{CaO}-\mathrm{SiO}_{2}$ onto the fabrics

For the in situ synthesis of only the $\mathrm{CaO}$ NPs onto the jute fabrics, $10 \mathrm{ml}$ of a $\mathrm{NaOH}$ aqueous solution $(1 \mathrm{M})$ were added drop by drop $(1 \mathrm{ml} / \mathrm{min})$ in $50 \mathrm{~mL}$ of a $\mathrm{Ca}\left(\mathrm{NO}_{3}\right)_{2}$ aqueous solution $(0.2 \mathrm{M})$, under mechanical stirring at $50{ }^{\circ} \mathrm{C}$ for $1 \mathrm{~h}$. Then, the samples were removed from the solution and heated at $150{ }^{\circ} \mathrm{C}$ for $6 \mathrm{~h}$. To perform the in situ synthesis of the $\mathrm{CaO}$ and $\mathrm{SiO}_{2}$ NPs the process was the same as the one referred before, until the end of the 1-hour time reaction. After the reaction mixture reached room temperature, $100 \mathrm{ml}$ of ethanol and $4 \mathrm{~mL}$ of $\mathrm{NH}_{3}$ were added. Then, $5 \mathrm{~mL}$ of a TEOS ethanolic solution $(50 \%$ vol TEOS in ethanol) were added dropwise, and the mixture was kept under constant stirring, at room temperature for $24 \mathrm{~h}$. At the end, the fabric samples were removed from the solution, and heated at $150{ }^{\circ} \mathrm{C}$ for $6 \mathrm{~h}$.

Sample characterization

\section{Attenuated Total Reflectance-Fourier Transform Infrared Spectroscopy (ATR-FTIR)}

The chemical composition of the developed systems was studied by ATR-FTIR analysis using an 
IRAffinity-1S, SHIMADZU equipment (Kyoto, Japan). The spectra were obtained in transmittance mode, in the range of $400-4000 \mathrm{~cm}^{-1}$. The samples were analysed 3 times in different places, in order to ensure the analysis' homogeneity.

\section{Ground-State Diffuse Reflectance (GSDR)}

The fabrics functionalized with the two types of NPs were analysed by GDSR. The transmittance and reflectance spectra were recorded using a Spectrophometer UV-2600 (Schimadzu) with the ISR_2600 Plus detector. The equipment was calibrated using as blank barium sulphate (full reflectance).

Different places of the samples were analysed, in order to ensure the analysis' homogeneity. The reflectance spectra were recorded, in the 200 to $700 \mathrm{~nm}$ wavelength, and the remission function was calculated accordingly with the Kubelka-Munk equation:

$\frac{K}{S}=\frac{[(1-R)]^{2}}{2 \times R}$

where $\mathrm{K}$ represents the absorption coefficient, $\mathrm{S}$ the dispersion coefficient and $\mathrm{R}$ the reflectance (Yang and Kruse 2004).

\section{Field Emission Scanning Electron Microscopy (FESEM) and Energy Dispersive Spectroscopy (EDS)}

The surface of the fabrics functionalized with the NPs was analysed by FESEM using NOVA 200 Nano SEM from FEI Company (Hillsboro, OR, USA). The samples were coated with a thin film $(20 \mathrm{~nm})$ of Gold $\mathrm{Au}$ ) and Palladium (Pd) before the analysis. The images were taken in topographic mode with an accelerated voltage of $10 \mathrm{kV}$. EDS technique (Hillsboro, OR, USA) coupled to FESEM was also performed, in order to evaluate the elemental composition of the samples, using EDAX Si(Li) detector with $15 \mathrm{kV}$ of acceleration voltage.

\section{$U V$-visible absorption spectra}

The UV-visible absorption spectra of the MB solutions were obtained using a Unicam double beam scanning UV-visible spectrophotometer
(ThermoFisher, Waltham, MA, USA) in the spectral range from 500 to $750 \mathrm{~nm}$ at room temperature. Several aliquots were collected from the solutions in study and diluted to prevent deviation from Beer's Law linearity.

\section{Thermogravimetric analysis (TGA)}

TGA analysis was performed using a STA 700 SCANSCI in order to do an estimation of the amount of NPs incorporated onto the jute fabrics. Jute fabrics without any functionalization and functionalized with $\mathrm{CaO}$ and $\mathrm{CaO}-\mathrm{SiO}_{2}$ NPs were subjected to a heating process from room temperature to $600{ }^{\circ} \mathrm{C}$ under nitrogen flow and with a heating rate of $20^{\circ} \mathrm{C} / \mathrm{min}$. The percentage of NPs was calculated using the following system of equations (Costa et al. 2018):

$\left\{\begin{array}{c}\text { NPs } \%+\text { jute fabric } \%\left(\frac{\text { jute fabrics residues } \%}{100}\right)=\text { sample total residues } \% \\ \text { NPs } \%+\text { jute fabrics } \%=100 \%\end{array}\right.$

Considering that the NPs have residues of $100 \%$ and the sample with NPs after thermal treatment is composed of NPs and jute fabric residue. Three replicates were analysed to ensure homogeneity.

Functional properties evaluation

\section{Water contact angle measurement}

In order to evaluate the hydrophobicity of the different functionalized fabric samples, the Water Contact Angle (WCA) was determined using a Contact Angle System (dataphysics) coupled to a high-resolution camera. To do the analysis, $5 \mu \mathrm{L}$ of distilled water were dispensed from the syringe onto the surface of the sample. Ten different places of each sample were measured, and the means and the standard deviations were calculated.

\section{UV protection}

In order to calculate the UPF and the UVA and UVB blocking values of the developed systems, the transmittance spectra of the samples were recorded in the 280-400 nm wavelength range, following EN137581, using a Spectrophotometer UV-2600 (Schimadzu) with the ISR_2600 Plus detector. Different places of 
the samples were analysed, in order to ensure the homogeneity of the analysis.

\section{Antibacterial activity tests}

The determination of antimicrobial activity was performed according to the internationally recognized Japanese industrial standard (JIS L 1902: 2002, "Testing method for antibacterial activity of textiles"). The method used was the absorption method, which is a quantitative one. The microorganisms assayed were the Gram-positive bacteria Staphylococcus aureus (ATCC 6538) and the Gram-negative bacteria Escherichia coli (ATCC 434). Briefly, inocula of $E$. coli and $S$. aureus were prepared in $20.0 \pm 0.1 \mathrm{~mL}$ of TSB (Tryptic Soy Broth, Merck) and incubated for a period of 18 to $24 \mathrm{~h}$ at $37 \pm 1{ }^{\circ} \mathrm{C}$ under agitation $(120 \mathrm{rpm})$. Samples were incubated for $24 \mathrm{~h}$ at $37 \pm 1{ }^{\circ} \mathrm{C}$, without agitation. Then, $5 \mathrm{~mL}$ of physiological saline solution $(8.5 \mathrm{~g}$ of $\mathrm{NaCl}$ and $2.0 \mathrm{~g}$ of non-ionic surfactant Tween 20 (Sigma Chemical Co.) per litre) were added to the samples, which were then vortexed ( 5 times, $5 \mathrm{~s}$ each time). The number of living cells was assessed by the serial dilution plate count method. All assays were performed in triplicate and repeated in three independent assays.

The percentage reduction of bacteria after $24 \mathrm{~h}$ incubation was calculated by the formula:

$\%$ Reduction $=[(\mathrm{B}-\mathrm{A}) / \mathrm{B}] \times 100$

where $\mathrm{A}=$ number of bacteria in the tested sample after $24 \mathrm{~h}, \mathrm{~B}=$ number of bacteria in the starting suspension before addition of the sample.

\section{Methylene blue degradation}

The photocatalytic activity of the $\mathrm{CaO}$ and $\mathrm{SiO}_{2} \mathrm{NPs}$ deposited on the fabrics was accessed by the degradation of MB as a model compound. The functionalized fabrics $(0.5 \mathrm{~g})$ were immersed in $25 \mathrm{~mL}$ of an aqueous solution of MB (10 mg/L) and irradiated by a UV blacklight lamp during 2, 5, 7 and $24 \mathrm{~h}$. Aliquots of the MB solution $(3 \mathrm{~mL})$, in contact with the different fabric samples, were withdrawn and their absorbance was measured by UV-Visible spectroscopy after the 2, 5, 7 and 24 h' time of UV irradiation, in order to monitor MB presence.

\section{Durability test: wash fastness}

In order to evaluate the wash durability of the nanocoating of $\mathrm{CaO}$ and $\mathrm{CaO}-\mathrm{SiO}_{2}$ onto the jute fabrics, jute, jute $+\mathrm{CaO}$ and jute $+\mathrm{CaO}-\mathrm{SiO}_{2}$ samples were placed in contact with distilled water and centrifugated at $200 \mathrm{rpm}$ for $6 \mathrm{~h}$, continuously. This procedure was adapted from the standard ISO6330Textiles, Domestic Washing and drying, procedures for textile testing, in order to mimic the domestic washing programmes. According with this standard the agitation speed could range between 119 and $179 \mathrm{rpm}$, for delicate and durable press parameters, respectively. The main goal of this procedure was made to assess if the NPs were fixed onto the fabrics, even after a continuous contact with water and under agitation.

To understand if the $\mathrm{CaO}$ and the $\mathrm{CaO}-\mathrm{SiO}_{2}$ NPs were still present in the jute surface after the washing tests, the colour change $(\Delta \mathrm{E})$, using the jute fabric as standard was determined before and after the fabrics washing process. The $\Delta \mathrm{E}$ was assessed in distinct places of the samples (three replicates) with a Datacolour spectrophotometer using the Cielab coordinates D65/10 software (Lucerne, Switzerland).

\section{Results and discussion}

In situ synthesis of the metal oxide nanoparticles onto the jute fabrics and respective characterization

As referred before, pre-treated jute fabrics were functionalized with $\mathrm{CaO}$ and $\mathrm{SiO}_{2}$ NPs by in situ synthesis. The experimental procedure is summarized in Fig. 1.

It should be remarked that common synthesis procedures of $\mathrm{CaO}$ NPs include the use of higher reducing agents' concentrations, higher calcination temperatures $\left(>500{ }^{\circ} \mathrm{C}\right)$ as well as longer reaction times. In this work, as Fig. 1 shows, the synthesis protocols were optimized in order to obtain these metal oxide NPs using the simplest approaches and also at the same time (one pot synthesis) reducing reactions times and reagents. As the following sections will show, the adopted experimental procedure was successful for the obtention of jute fabrics functionalized with hierarchical structures of $\mathrm{CaO}-\mathrm{SiO}_{2} \mathrm{NPs}$. 
(a)

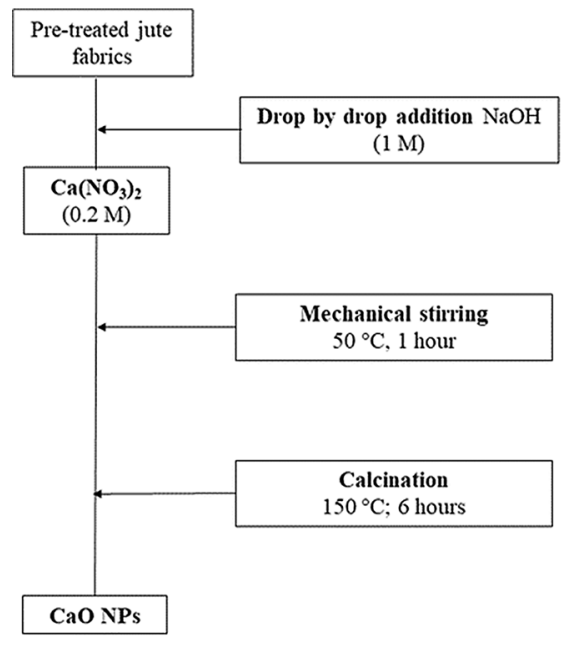

(b)

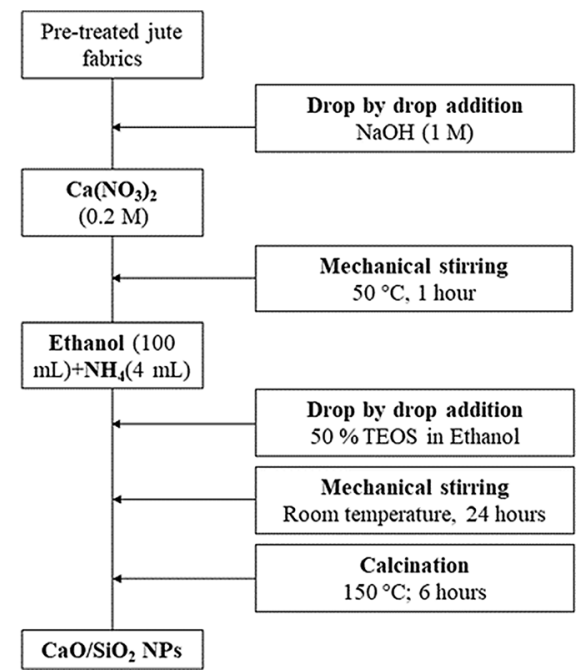

Fig. 1 Schematic diagram of the experimental procedure for $\mathbf{a}$ in situ synthesis of $\mathrm{CaO}$ NPs onto the fabrics and $\mathbf{b}$ in situ synthesis of $\mathrm{CaO}-\mathrm{SiO}_{2}$ onto the fabrics

\section{Attenuated Total Reflectance-Fourier Transform Infrared Spectroscopy (ATR-FTIR)}

Figure 2 exhibits the ATR-FTIR spectra of jute fabric, jute fabric functionalized with $\mathrm{CaO}$ NPs and jute with $\mathrm{CaO}-\mathrm{SiO}_{2}$ NPs.

The jute fabric spectrum shows the presence of the typical bands of natural cellulosic fibers: cellulose, hemicellulose and lignin. It's possible to see the appearance of a band, at approximately $3300 \mathrm{~cm}^{-1}$, corresponding to the $\mathrm{O}-\mathrm{H}$ stretching, related to the hydroxyl groups from cellulose and lignin and also to the existence of adsorbed water molecules (P Ferreira et al. 2018; Zouheyr et al. 2015). The band peaking at $\sim 2900 \mathrm{~cm}^{-1}$, can be attributed to the asymmetric $\mathrm{C}-\mathrm{H}$ stretching vibration of cellulose and hemicellulose (P Ferreira et al. 2018; Zouheyr et al. 2015) and the one peaking around $1020 \mathrm{~cm}^{-1}$ is related to the C-O stretch vibration (Silva et al. 2016). The in situ synthesis of $\mathrm{CaO}$ NPs onto the jute, resulted in the appearance of the characteristic fingerprint peaks of $\mathrm{CaO}$ metal oxide, namely: $\mathrm{O}-\mathrm{H}$ from $\mathrm{Ca}(\mathrm{OH})_{2}, \mathrm{C}-\mathrm{O}$, $\mathrm{Ca}-\mathrm{O}-\mathrm{Ca}$ and $\mathrm{Ca}-\mathrm{O}$ bondings at $3640 \mathrm{~cm}^{-1}$, $1400 \mathrm{~cm}^{-1}, 870 \mathrm{~cm}^{-1}$ and $710 \mathrm{~cm}^{-1}$ respectively (Anantharaman et al. 2016; Bharathiraja et al. 2018; Galván-Ruiz et al. 2009; Tangboriboon et al. 2012). In addition, due to the high reflective index of $\mathrm{CaO}$ NPs coating (S Anesh et al. 2015) onto the jute surface, there is no evidence of the peaks related with the

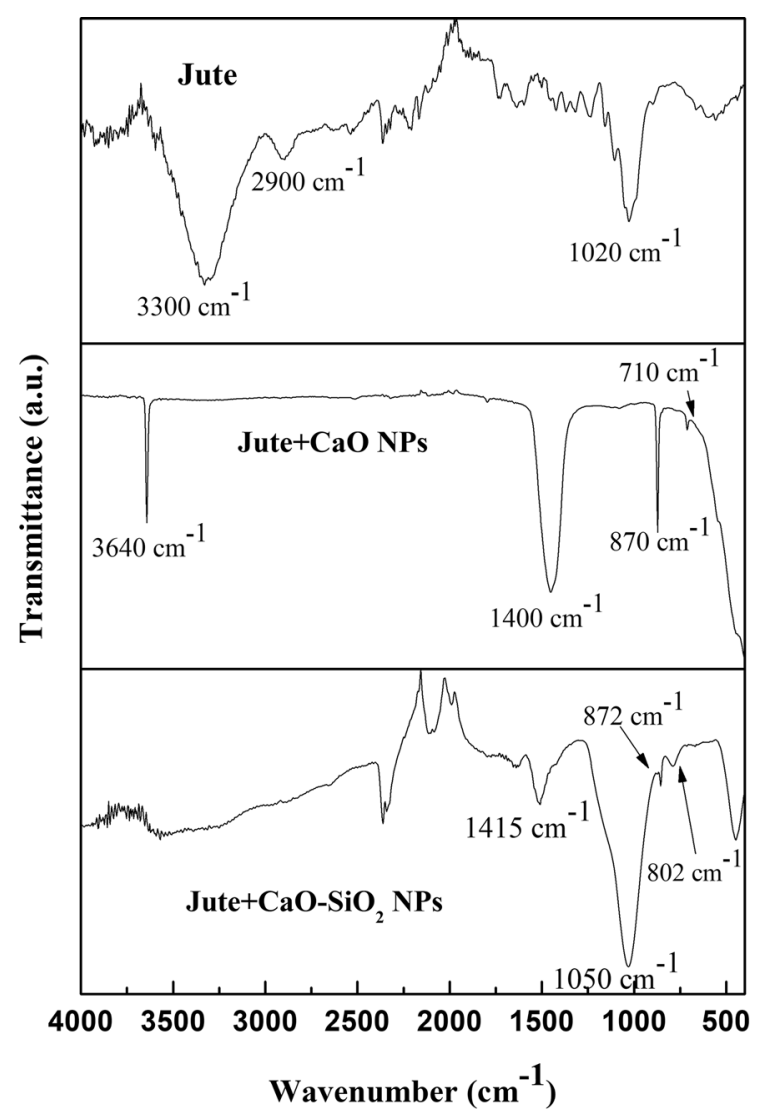

Fig. 2 ATR-FTIR spectra of jute fabric, jute functionalized with $\mathrm{CaO}$ NPs and jute with $\mathrm{CaO}-\mathrm{SiO}_{2} \mathrm{NPs}$ 
natural fiber, possibly indicating the full covering of the analysed surface with the NPs, which is not allowing the appearance of cellulose characteristic bands observed in the jute spectrum. The $\mathrm{SiO}_{2} \mathrm{NPs}$ addition, led to the appearance of two new bands peaking at $1050 \mathrm{~cm}^{-1}$ and $802 \mathrm{~cm}^{-1}$ correspondent to asymmetrical stretching vibration of the $\mathrm{Si}-\mathrm{O}-\mathrm{Si}$ bonds, characteristic of the $\mathrm{SiO}_{2}$ NPs formation ( $\mathrm{Li}$ et al. 2014; El-Naggar et al. 2017). Due to the high intensity of the $1050 \mathrm{~cm}^{-1}$ band, the fingerprint bands of $\mathrm{CaO}$ (at 1415 and $872 \mathrm{~cm}^{-1}$ ) are present in the spectrum, however with lower intensity when compared with the spectrum of jute $+\mathrm{CaO}$ NPs. In the spectrum of jute $+\mathrm{CaO}-\mathrm{SiO}_{2} \mathrm{NPs}$ is also visible a very broad band between the 3200 and $3500 \mathrm{~cm}^{-1}$. The absorption bands peaking in this wavenumber range correspond to the stretching vibration of the $\mathrm{O}-$ $\mathrm{H}$ or $\mathrm{Si}-\mathrm{OH}$ bonds, possibly indicating the establishment of hydrogen bonds between the hydroxyl groups of the jute and the NPs (Ferreira et al. 2016; El-Naggar et al. 2017). The existence of these hydrogen bonds leads to the conclusion that the NPs are anchored to the jute fabric surface.

\section{Ground-State Diffuse Reflectance (GSDR)}

The Kubelka-Munk remission functions of the jute fabrics without any functionalization and functionalized with $\mathrm{CaO}$ and with $\mathrm{CaO}-\mathrm{SiO}_{2}$ NPs are shown in Fig. 3.

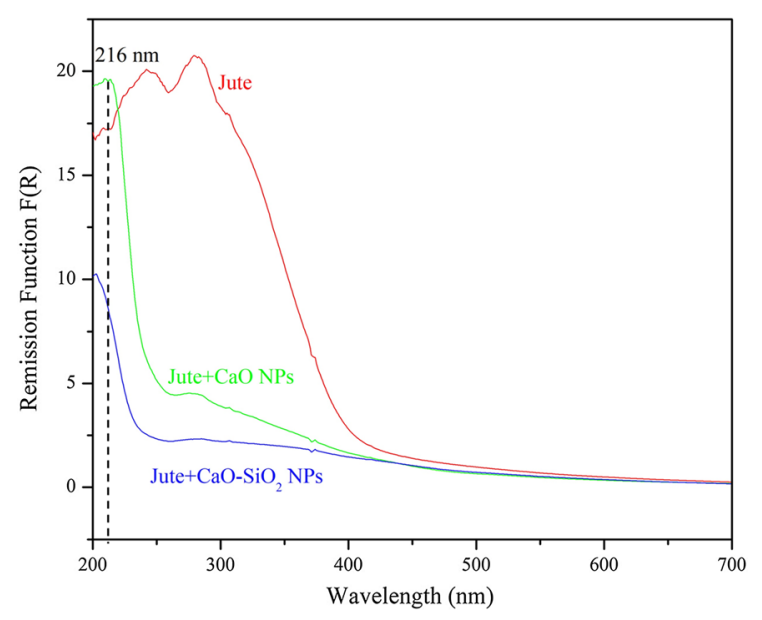

Fig. 3 GSDR spectra of the non-functionalized jute fabric (red), jute fabric functionalized with $\mathrm{CaO}$ NPs (green) and jute fabric functionalized with $\mathrm{CaO}-\mathrm{SiO}_{2} \mathrm{NPs}$ (blue)
The fabric functionalized with $\mathrm{CaO}$ NPs present a new peak, when compared with the spectra of the nonfunctionalized fabric, at approximately $216 \mathrm{~nm}$. This peak is probably related to the presence of the $\mathrm{CaO}$ NPs, confirming once again the successful incorporation of these NPs onto the fabric's surface. It's also possible to observe that, for the samples with NPs in their surface, there's a decrease in the absorption band intensity, when compared with the jute fabric without NP's. There's a decrease in the absorption intensity related to an increase of the reflectance. This phenomenon can be attributed to the presence of the NPs onto the surface of the fabrics, since they are inorganic white-pigments at nanoscale, which intrinsically present a high reflective index, easily reflecting the UV rays (S Anesh et al. 2015). The intensity of band related to the $\mathrm{CaO}$ NPs also decreases for the samples with $\mathrm{CaO}-\mathrm{SiO}_{2} \mathrm{NPs}$, this can be explained by the loss of some $\mathrm{CaO}$ NPs in the process of the addition of the $\mathrm{SiO}_{2}$ NPs (Costa et al. 2018).

\section{Field Emission Scanning Electron Microscopy (FESEM) and Energy Dispersive Spectroscopy (EDS)}

The surface morphology of the pre-treated jute fabric and the jute fabric functionalized with $\mathrm{CaO}$ and $\mathrm{CaO}-$ $\mathrm{SiO}_{2}$ NPs by in situ synthesis were evaluated by FESEM. EDS analysis of these samples was also performed in order to evaluate their elemental composition and the presence of Silica (Si) and Calcium (Ca) at the fabrics surface (Fig. 4 and Fig. 5).

Figure 4a exhibits the smooth and cleaned pretreated jute fabric surface without NPs for comparison purposes. Figure $4 \mathrm{~b}-\mathrm{e}$ show the distribution of $\mathrm{CaO}$ NPs onto the fabric surface using different magnifications (from 200 to $2 \mu \mathrm{m}$ ). As the images show, the NPs have a spherical shape distributed all over the fiber surface with the presence of some aggregates. From FESEM images in Fig. $4 \mathrm{f}-\mathrm{i}$, it might be observed the presence of both NPs onto the fibers surface. In fact, the particles morphology is the same (spherical shape) and they are also covering all the surface. The obtained EDS spectra of jute, jute $+\mathrm{CaO}$ NPs and jute + $\mathrm{CaO}-\mathrm{SiO}_{2}$ NPs is presented in Fig. 5.

As expected, the EDS analysis confirms the existence of the peaks related with the presence of $\mathrm{Ca}$ and $\mathrm{Si}$ onto the jute fabrics surface. Through the ATRFTIR, GSDR and FESEM-EDS analysis is possible to confirm that the NPs were synthetized successfully 

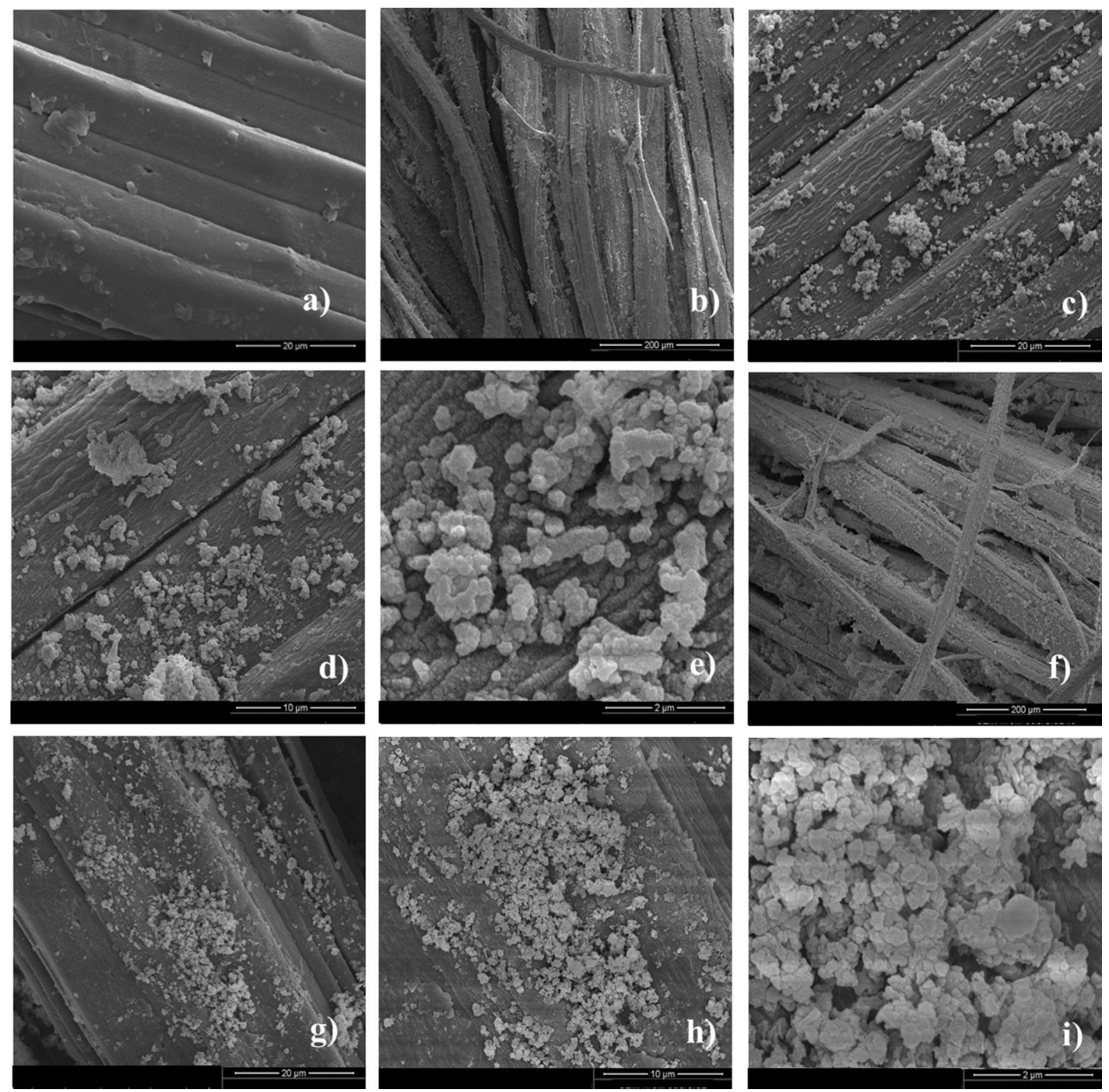

Fig. 4 FESEM images of a jute fabric surface; $\mathbf{b}-\mathbf{e}$ images of jute fabric functionalized with CaO NPs using different magnifications respectively $(200,20,10$ and $2 \mu \mathrm{m})$ and $\mathbf{f}-\mathbf{i}$ jute fabric functionalized with $\mathrm{CaO}-\mathrm{SiO}_{2} \mathrm{NPs}(200,20,10$ and $2 \mu \mathrm{m})$

onto the surface of the jute fabrics. Most syntheses reported in literature use very high calcination temperatures, between 500 and $700{ }^{\circ} \mathrm{C}$ (Alavi and Morsali 2010; Anantharaman et al. 2016; Bharathiraja et al. 2018). In this work, the calcination temperature used was $150{ }^{\circ} \mathrm{C}$, a lot less than the ones already reported. With this work, it was demonstrated that this temperature is enough to effectively obtain $\mathrm{CaO}$ NPs.
The use of lower temperatures makes this synthesis more sustainable and easier to apply at industrial scale.

\section{Thermogravimetric analysis (TGA)}

The previous techniques allowed the investigation of the morphology and qualitative chemical information of the synthesized NPs. Thermogravimetric analysis (TGA) can be used for the quantitative analysis and 


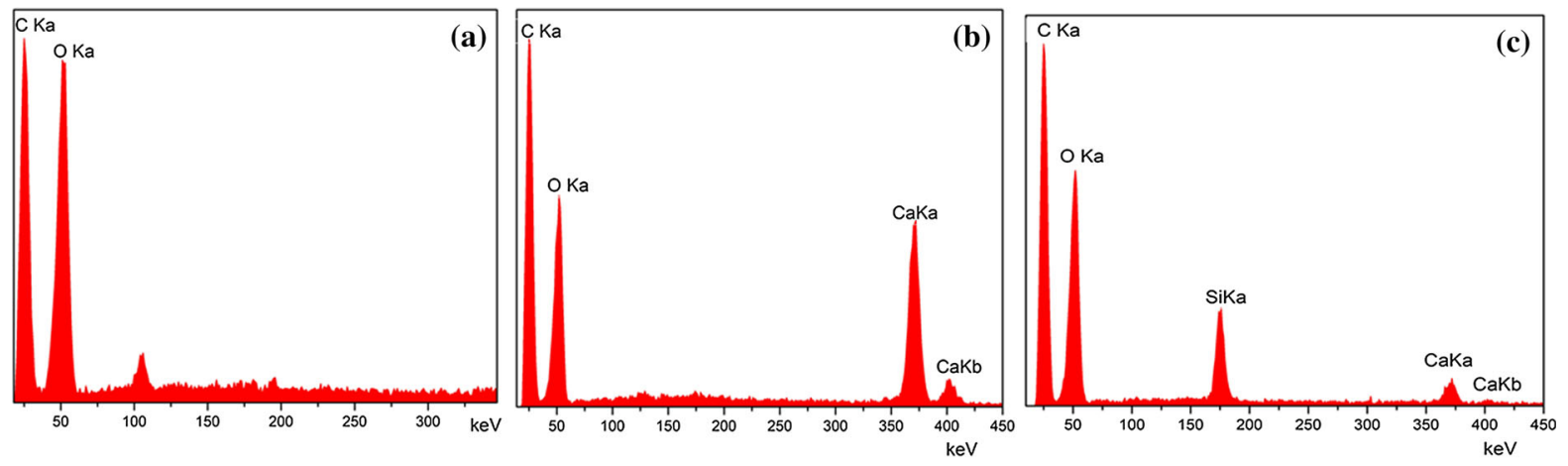

Fig. 5 EDS analysis of $\mathbf{a}$ jute fabric surface; $\mathbf{b}$ jute $+\mathrm{CaO}$ NPs and $\mathbf{c}$ jute $+\mathrm{CaO}-\mathrm{SiO}_{2} \mathrm{NPs}$

give us information about the amount of the NPs onto the fabric surface.

For this purpose, the jute fabric sample and the sample of jute with $\mathrm{CaO}-\mathrm{SiO}_{2} \mathrm{NPs}$ were tested. The samples were subjected to a heating process from 25 to $600{ }^{\circ} \mathrm{C}$ and all the weight losses were considered giving special attention to the percentage of residues of each sample at the end of the heating process. The percentage of $\mathrm{CaO}-\mathrm{SiO}_{2} \mathrm{NPs}$ was calculated using the equation system referred before. The jute fabric without NPs presented $1.62 \mathrm{wt} \%$ of residues, and the jute fabric functionalized with $\mathrm{CaO}-\mathrm{SiO}_{2}$ NPs presented $2.68 \mathrm{wt} \%$. Considering that the final sample is composed by the jute fabric and the NPs, the percentage of NPs present at the fabric surface is approximately $1.06 \mathrm{wt} \%$.

Functional properties evaluation

\section{Hydrophobicity properties}

The hydrophobicity of the jute fabric's surface was evaluated by the measurement of the WCA in 10 different places of the samples, in order to ensure homogeneity. If the obtained WCA is smaller than $90^{\circ}$, the surface is considered hydrophilic, but if the WCA is higher than $90^{\circ}$, the surface is considered hydrophobic. For a surface to be considered superhydrophobic, the WCA has to be bigger than $150^{\circ}$ (Marmur et al. 2017). The results of these measurements are shown in Fig. 6.

Jute fabric is hydrophilic by nature with a WCA of $0^{\circ}$. The incorporation of $\mathrm{CaO}$ NPs onto the jute fabrics' surface leads to a WCA of $89.7^{\circ}$, so it's possible to say that we started with a hydrophilic surface, and with the functionalization of the fabric with $\mathrm{CaO}$ NPs we obtained a hydrophobic surface. However, with the addition of the $\mathrm{SiO}_{2} \mathrm{NPs}$ to the jute $+\mathrm{CaO}$ NPs systems, there's an increase in the WCA, reaching almost super-hydrophobicity $\left(143.7^{\circ}\right)$. This result is in accordance with the well know hydrophobic character of $\mathrm{SiO}_{2} \mathrm{NPs}$ (Jhatial et al. 2019; Seyfi et al. 2016) and can be very useful for self and easy cleaning applications.

\section{UV protection}

The UV protection properties of the developed systems were also evaluated. In order to do this, the UPF, UVA and UVB blocking were calculated, recurring to the standard EN13758-1. These values, for the non-functionalized pre-treated jute fabric and for the jute fabric functionalized with $\mathrm{CaO}$ and $\mathrm{CaO}-$ $\mathrm{SiO}_{2}$ NPs are presented in Table 1 .

From the results of Table 1, it's clear that the jute fabric without any kind of NPs have almost no UV protection, presenting a UPF of 8 . Nevertheless, metal oxide NPs are used as UV blocking agents (Nallathambi 2011), and the obtained results for the fabrics functionalized with the NPs are in conformity with this information. The UV protection capability of metal oxides can be explained by several approaches. One of them states that this type of NPs reflects and/or scatters the UV rays, and another one focus one the semiconductive properties of metal oxides, leading to UV radiation absorption. This mechanism for semiconducting inorganic materials can be described by the use of photon energy in order to excite electrons from the valence to the conduction band (Bashari et al. 2019). 


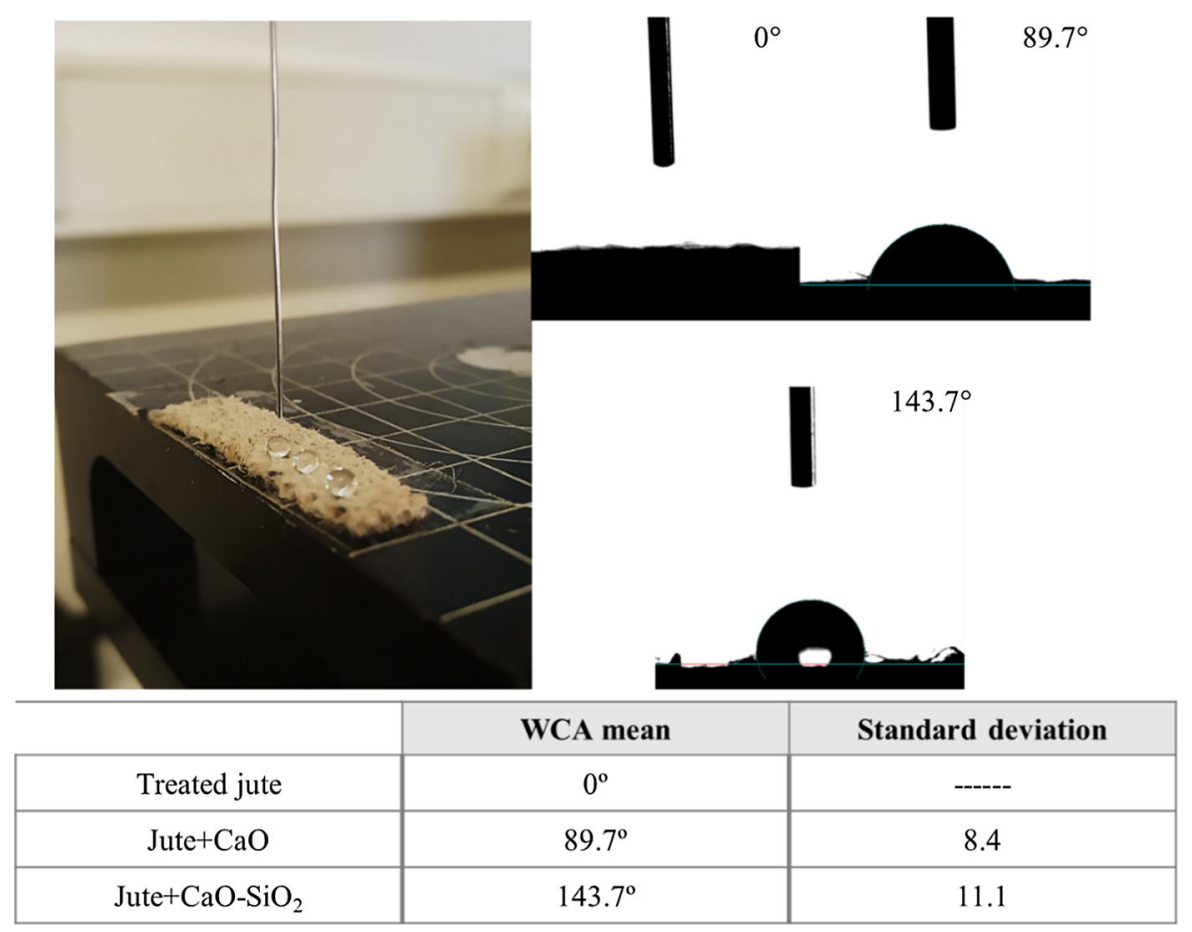

Fig. 6 WCA measurements of the non-functionalized pretreated jute fabric, jute fabric functionalized with CaO NPs and jute fabric functionalized with $\mathrm{CaO}-\mathrm{SiO}_{2}$ NPs. Representative image of the jute fabric functionalized with $\mathrm{CaO}$ NPs

Table 1 UPF, classification and UVA and UVB blocking (\%) values of the jute, jute $+\mathrm{CaO}$ and jute $+\mathrm{CaO}_{-} \mathrm{SiO}_{2} \mathrm{NPs}$ samples

\begin{tabular}{lrlll}
\hline Sample & UPF & Classification & UVA blocking (\%) & UVB blocking (\%) \\
\hline Jute & 8 & Low protection & 82.1 & 89.6 \\
Jute $+\mathrm{CaO} \mathrm{NPs}$ & 159 & Excellent & 99.3 & 99.4 \\
Jute $+\mathrm{CaO}-\mathrm{SiO}_{2} \mathrm{NPs}$ & 425 & Excellent & 99.8 & 99.8 \\
\hline
\end{tabular}

With the functionalization of the fabrics with the $\mathrm{CaO}$ NPs, the UPF value increases to 159 , which means that these are classified as excellent, for UV protection purposes. For the jute fabric functionalized not only with $\mathrm{CaO}$ but also with $\mathrm{SiO}_{2} \mathrm{NPs}$, this UPF value increased even more, reaching 425 . Thus, the addition of $\mathrm{SiO}_{2} \mathrm{NPs}$ to the functionalization of the fabrics, improves the UV protection properties of the textiles. This result, once again, confirms the enhancement of the $\mathrm{CaO}$ NPs properties, with the addition of the $\mathrm{SiO}_{2}$ NPs (Peerzada et al. 2019).

\section{Antibacterial activity}

Several studies have reported the use of plant extracts as effective antimicrobial agents, namely, extracts of the leaves and aerial parts of Corchorous olitorius (origin of jute fibers) (Sümengen Özdenefe et al. 2019). At the same time, the antimicrobial effect of blast fibers (like hemp, bamboo and flax) has already been reported (Cai and Ma 2013). Jute fibers present a lignin content of approximately $16 \%$, which is a very high value when compared with other bast fibers, such as hemp or flax, with a lignin content less than 5\% (del Río et al. 2009). In this specific case, the raw jute fabrics that were used, were only treated with detergent, in order to eliminate the dirt and waxes present 
on the fiber's surface. Thus, the chemical composition of the fibers was not changed (contrary to what happens in the alkali treatment, for example), having still a great quantity of lignin. Some studies already demonstrated that lignin has an antimicrobial effect, since the phenolic hydroxyl and methoxy groups that constitute it are biologically active (Alzagameem et al. 2019). This can explain the potential antibacterial activity of raw jute fibres.

Accordingly, the antibacterial activity of jute fabrics and jute fabrics functionalized with $\mathrm{CaO}$ and $\mathrm{CaO}-\mathrm{SiO}_{2}$ NPs was assessed in accordance with Japanese Standard JIS L 1902:2002. Gram-negative (Escherichia coli) and Gram-positive (Staphylococcus aureus) bacteria were tested and the results are presented in Table 2.

Typically, an antimicrobial agent may possess either bactericidal or bacteriostatic properties. Bactericidal activity implies the forthright killing of the organisms (killing of $>99.9 \%$ ) while bacteriostatic activity is defined as maintenance of the original inoculum concentration, which means that it prevents the multiplication of bacteria without destroying it. In this study, the three samples presented bacteriostatic activity against both microorganisms, but the enhancement of the antimicrobial properties is obtained with the addition of the $\mathrm{CaO}$ and $\mathrm{SiO}_{2}$ NPs. The antibacterial activity of lignocellulosic fibers, with similar lignin contents to the jute fibers, has already been reported, where it was also demonstrated that the antibacterial activity is related to the phenolic content in the material (Guna and Ilangovan 2018; Ilangovan et al. 2020). This is in accordance with the obtained results, since the jute fibers utilized were in their raw form, therefore presenting a great content of lignin.

In fact, although the jute fabrics per si already have antimicrobial properties, when functionalized with $\mathrm{CaO}$ NPs present bactericidal properties against $S$. aureus. This is in accordance with the results of Roy and co-authors (Roy et al. 2013) when studied the antimicrobial activities of CaO NPs against Staphylococcus epidermidis (Gram-positive) and Pseudomonas aeruginosa (Gram-negative). They observed that the bactericidal concentration of $\mathrm{CaO}$ NPs was quite lower for Staphylococcus epidermidis in comparison to Gram negative Pseudomonas aeruginosa. This can be due to the higher amount of negatively charged peptidoglycans that would make Gram positive bacteria more susceptible to such positively charged antimicrobials (Ren et al. 2009). This is also in accordance with the obtained results, as the antibacterial activity of the functionalized samples was more pronounced against the gram-positive bacteria, when compared with the gram-negative one. Although, the results of antibacterial activity against $E$. coli were also very good, once again demonstrating the great antimicrobial potential of these systems. It's also possible to conclude, that for this specific property, the addition of the $\mathrm{SiO}_{2} \mathrm{NPs}$ didn't had a significant impact, since the obtained antibacterial activity values, for the two types of bacteria, of the jute fabric with $\mathrm{CaO}$ is not very different that the ones obtained for the jute fabric with $\mathrm{CaO}$ and $\mathrm{SiO}_{2}$ NPs. These results confirm that jute fibers, and in particular jute fabrics functionalized with $\mathrm{CaO}$ and $\mathrm{CaO}-\mathrm{SiO}_{2}$ NPs present great antibacterial properties, hence they can be used for multiple antibacterial applications, namely in personal protective equipment.

\section{Methylene blue degradation tests}

The photocatalytic activity of the $\mathrm{CaO}$ and $\mathrm{CaO}-\mathrm{SiO}_{2}$ NPs was evaluated through the monitorization by UVspectroscopy of MB degradation. For this purpose, the functionalized jute fabrics (with $\mathrm{CaO}$ or $\mathrm{CaO}-\mathrm{SiO}_{2}$ NPs) were immersed onto the MB solution and kept in the dark for $10 \mathrm{~min}$ to ensure the adsorption-desorption equilibrium. After this time, the samples were irradiated by UV light and several aliquots of the MB

Table 2 Antibacterial activity $(\%)$ values of the jute, jute $+\mathrm{CaO}$ and jute $+\mathrm{CaO}-\mathrm{SiO}_{2} \mathrm{NPs}_{\text {samples }}$

\begin{tabular}{llr}
\hline Sample & Staphylococcus aureus & Escherichia coli \\
\hline Jute & $81.74 \pm 9.50$ & $95.84 \pm 3.68$ \\
Jute $+\mathrm{CaO} N P s$ & $99.98 \pm 0.03$ & $98.25 \pm 2.38$ \\
Jute $+\mathrm{CaO}-\mathrm{SiO}_{2} \mathrm{NPs}$ & $99.96 \pm 0.07$ & $99.80 \pm 0.29$ \\
\hline
\end{tabular}


solution (in contact with the fabric samples) were collected, after 2, 5, 7 and $24 \mathrm{~h}$ of UV radiation. For comparison purposes, the control solution of only MB in water was also monitored. Figure 7 show the obtained UV-Vis spectra of the three different samples under study: jute $+\mathrm{CaO}$, jute $+\mathrm{CaO}-\mathrm{SiO}_{2}$ and control solution.

Through the study of the spectra of the two different types of NPs, it's visible that over time and with UV light exposure, the intensity of the band peaking at $664 \mathrm{~nm}$ (characteristic absorption band of MB (Yang et al. 2017)) decreased. When reaching the 24 h' time, the band related to the dye almost disappears, which indicates that the $\mathrm{MB}$ was degraded. When comparing the jute $+\mathrm{CaO}$ spectra with jute $+\mathrm{CaO}-\mathrm{SiO}_{2}$, it may be

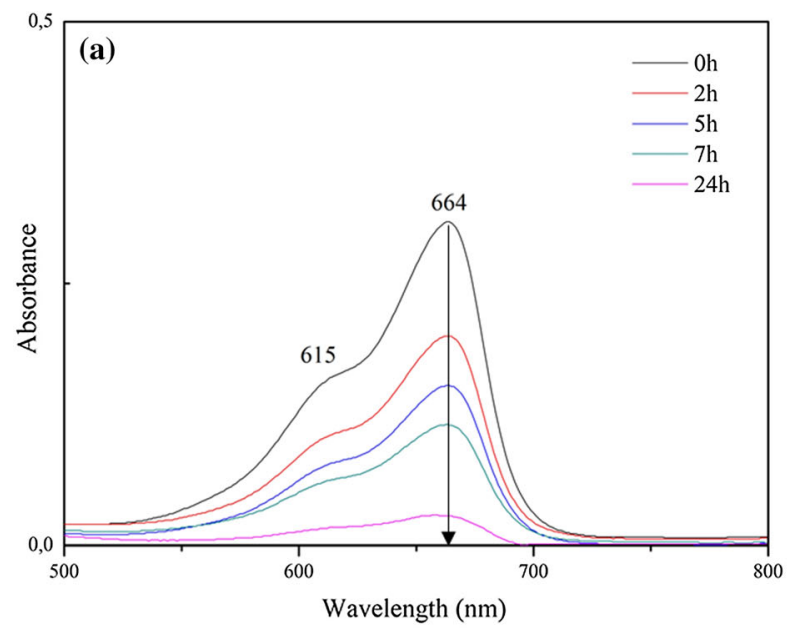

concluded that for the last system, the MB degradation is faster. For the 2-hour time, the absorbance at $664 \mathrm{~nm}$ for the jute $+\mathrm{CaO}$ was 1.3 , yet, for the jute $+\mathrm{CaO}-\mathrm{SiO}_{2}$ was 0.9. Regarding the 7-hour time, the measured absorbance was 0.5 for jute $+\mathrm{CaO}$ and 0.2 for the jute $+\mathrm{CaO}-\mathrm{SiO}_{2}$. This is probably related to the improvement of the photocatalytic activity of $\mathrm{CaO}$, with the addition of the $\mathrm{SiO}_{2} \mathrm{NPs}$, which is an accordance with literature, since $\mathrm{SiO}_{2}$ improved photocatalysis has been reported for other metal oxide NPs (Guan 2005). It's also possible to observe in the control dye solution spectrum, that the intensity of the band peaking at $664 \mathrm{~nm}$ stays almost the same over time, which means that without the presence of the NPs the MB degradation doesn't occur.

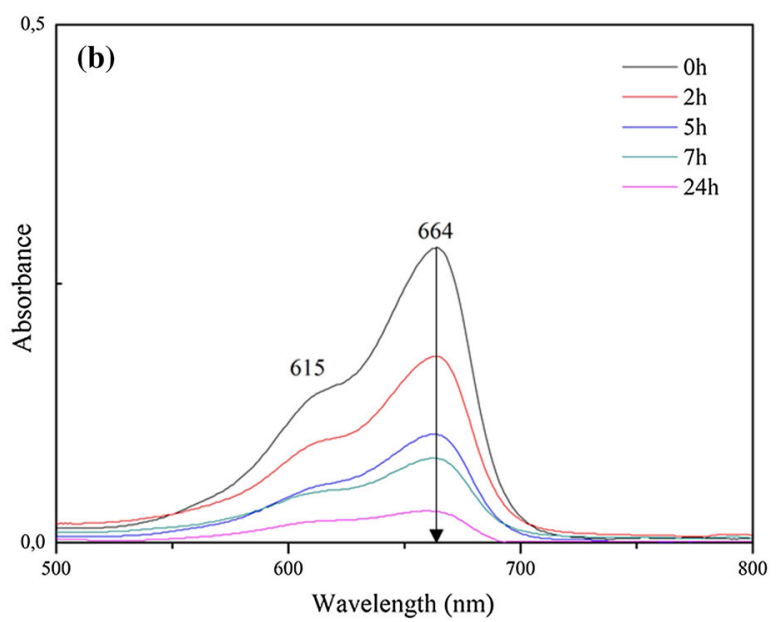

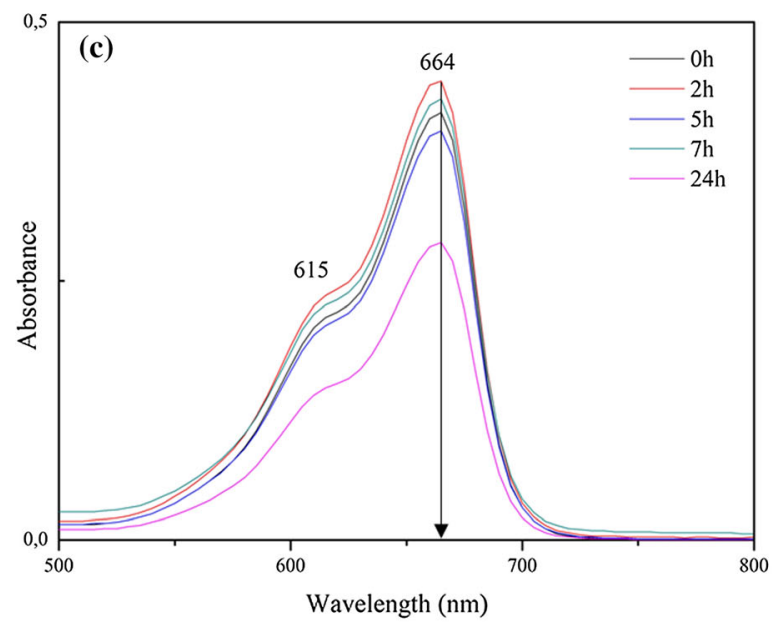

Fig. 7 Absorbance spectra of MB solution after 2, 5, 7 and 24 h of UV irradiation for a jute fabrics functionalized with CaO NPs, b functionalized with $\mathrm{CaO}-\mathrm{SiO}_{2} \mathrm{NPs}$ and $\mathbf{c}$ for the MB solution (control) 
The photodegradation of reactive dyes, using $\mathrm{CaO}$ and $\mathrm{SiO}_{2}$ NPs as the photocatalyst has already been studied (Badr et al. 2008; Kornprobst and Plank 2012; Veeran et al. 2014). The degradation of specifically MB by this kind of NPs was also already demonstrated (Ameta et al. 2014). Thus, the mechanism of photocatalytic degradation of the $\mathrm{CaO}-\mathrm{SiO}_{2} \mathrm{NPs}$ can be predicted:

$$
\begin{aligned}
& \mathrm{NPs}+h v \rightarrow\left(e_{\mathrm{CB}}^{-}+h_{V B}^{+}\right) \\
& e_{\mathrm{CB}}^{-}+\mathrm{O}_{2} \rightarrow \mathrm{O}^{2 \cdot-} \\
& \mathrm{H}_{2} \mathrm{O}+\mathrm{O}^{2 \cdot-} \rightarrow \mathrm{OOH}+\mathrm{OH} \\
& 2 \mathrm{OOH} \rightarrow \mathrm{O}_{2}+\mathrm{H}_{2} \mathrm{O}_{2} \\
& \mathrm{O}_{2}^{--}+\text {dye } \rightarrow \text { dye }-\mathrm{OO} \\
& \mathrm{OOH}^{-}+\mathrm{H}_{2} \mathrm{O}+e_{\mathrm{CB}}^{-} \rightarrow \mathrm{H}_{2} \mathrm{O}_{2}+\mathrm{OH}^{-} \\
& \mathrm{H}_{2} \mathrm{O}_{2}+e_{\mathrm{CB}}^{-} \rightarrow \mathrm{OH}^{-}+\mathrm{OH}^{-} \\
& \mathrm{H}_{2} \mathrm{O}_{2}+\mathrm{O}_{2}^{--} \rightarrow \mathrm{OH}^{-}+\mathrm{OH}^{-}+\mathrm{O}_{2} \\
& \mathrm{OH}^{\cdot} / \mathrm{O}_{2}^{--} / \mathrm{NPs}^{+}+\text {dye } \rightarrow \text { Dye degradation }
\end{aligned}
$$

Under UV radiation, the $\mathrm{CaO}-\mathrm{SiO}_{2} \mathrm{NPs}$ molecules get excited, transferring one electron to the conduction band (1). This electron in the NPs' conduction band can reduce the molecular oxygen, producing a super oxide radical (2). The molecular oxygen adsorbed on the surface of the NPs, prevents the hole-electron pair recombination. This process decreases the rate of the photocatalytic degradation. In the presence of oxygen and organic molecules, the super oxide radical may form hydrogen peroxide or organic peroxide (3-5). Another path can also generate hydrogen peroxide (6) and this compound can form hydroxyl radicals, which are powerful oxidizing agents $(7,8)$. The produced radicals by this reaction are able of attack dye molecules and degrade them (9) (Ameta et al. 2014).

The degradation of MB was used as model reaction in order to evaluate the photocatalyst activity of the NPs, due to the obvious color change during the reaction (Yang et al. 2017). In future works, this photocatalytic activity is going to be evaluated for other dyes and toxic chemicals.

\section{Durability test: wash fastness}

For the washing test, the fabric samples were immersed in water and subjected to centrifugation treatment (to mimic the washing machine process as referred in the experimental part). The samples were dried and Cielab color coordinate, namely $\Delta \mathrm{E}$ was measured in three different sites of each sample (jute $+\mathrm{CaO}$ and jute $+\mathrm{CaO}-\mathrm{SiO}_{2}$ ) and using the jute fabric as standard.

In Table 3, the average values of $\Delta \mathrm{E}$ before and after the washing test are presented.

For the jute sample loaded with $\mathrm{CaO}$ NPs, visible quantity of NPs was released into the solution resulting in a decrease of the $\Delta \mathrm{E}$ from 4.5 to 2.6 (color fading). This release is related with the weak attachment of the excess $\mathrm{CaO}$ NPs onto the jute fabric surface. However, after six hours of continuous washing there is still half of the NPs initial quantity at the jute surface. Regarding the sample of jute + $\mathrm{CaO}-\mathrm{SiO}_{2}$ NPs the variation is very small, almost undetectable (from 5.7 to 5.4). In fact, The $\mathrm{SiO}_{2} \mathrm{NPs}$ improved the attachment of the NPs to the fabric and the $\Delta \mathrm{E}$ values remained constant. $\mathrm{SiO}_{2} \mathrm{NPs}$ could be covalently bounded to the jute surface by silanes through $-\mathrm{O}-\mathrm{Si}-\mathrm{O}-$ or $-\mathrm{CH}_{2}-\mathrm{O}-\mathrm{Si}-\mathrm{O}-$ groups (Roe and Zhang 2009) disabling the release of the NPs onto the water as happened when only $\mathrm{CaO}$ NPs were

\begin{tabular}{|c|c|}
\hline Sample & $\Delta \mathrm{E}$ \\
\hline Jute $+\mathrm{CaO}$ NPs before wash & 4.5 \\
\hline Jute $+\mathrm{CaO}$ NPs after wash & 2.6 \\
\hline Jute $+\mathrm{CaO}-\mathrm{SiO}_{2} \mathrm{NPs}$ before wash & 5.7 \\
\hline Jute $+\mathrm{CaO}-\mathrm{SiO}_{2}$ NPs after wash & 5.4 \\
\hline
\end{tabular}
present onto the jute. Overall, despite the variation exhibited by the sample with $\mathrm{CaO}$ NPs, the $\mathrm{CaO}-\mathrm{SiO}_{2}$ NPs fabric displayed an excellent performance after the washing test being the most promising sample under study.

Table $3 \Delta \mathrm{E}$ values for the Jute $+\mathrm{CaO}$ NPs before and after wash and for Jute $+\mathrm{CaO}-\mathrm{SiO}_{2}$ NPs before and after wash samples compared with jute fabric 


\section{Conclusion}

This works presents, for the first time in literature, the in situ synthesis of $\mathrm{CaO}$ and $\mathrm{SiO}_{2} \mathrm{NPs}$ onto jute fabrics, in order to obtain a multifunctional material. The two types of NPs were successfully synthesized onto the surface of the pre-treated jute fabrics, through sustainable and simple processes and materials.

ATR-FTIR, GSDR and FESEM-EDS results confirmed the presence of not only the $\mathrm{CaO}$, but also the $\mathrm{SiO}_{2} \mathrm{NPs}$ onto the fabrics surface. The ATR-FTIR results, particularly, besides confirming the presence of the NPs onto the jute fabrics also showed that they were well anchored to the fabrics, since there's the establishment of hydrogen bonds between the hydroxyl groups of the jute and the NPs. The FESEM images also revealed that the NPs presented a spherical shape and a homogeneous distribution all over the jute surface. The developed systems presented great properties, namely hydrophobicity, UV protection, antibacterial activity and MB degradation. Regarding the hydrophobicity, the pretreated jute fabrics presented a hydrophilic character, with a WCA of $0^{\circ}$, nonetheless, the functionalization of the fabrics with $\mathrm{CaO}$ led to hydrophobicity, presenting a WCA of 89. $7^{\circ}$. However, the addition of $\mathrm{SiO}_{2} \mathrm{NPs}$ increased the WCA of the jute fabrics, reaching almost superhydrophobicity, with a WCA of $143.7^{\circ}$. The functionalized jute fabrics also presented very good UV protection values, with UPF values of $50+$, and with UVA and UVB blocking values of almost $100 \%$. In this case, the addition of the $\mathrm{SiO}_{2}$ improved once again the properties of the systems, since the UPF obtained for the jute $\mathrm{CaO}$ sample was 159 , increasing to 425 for the jute $\mathrm{CaO}-\mathrm{SiO}_{2}$ sample. Regarding the antibacterial activity, all the samples, including the non-functionalized jute fabrics presented bacteriostatic activity against two types of bacteria, Escherichia coli and Staphylococcus aureus, but an enhancement of the antimicrobial properties was observed with the addition of the $\mathrm{CaO}$ and $\mathrm{SiO}_{2}$ NPs, reaching values of $99.8 \%$ of antibacterial activity against the two microorganisms. The developed samples also showed photocatalytic activity, being able to degrade MB. Once again, the presence of the $\mathrm{SiO}_{2}$ NPs improved the obtained results as the MB degradation was faster for the sample with these NPs, when compared with the samples with only $\mathrm{CaO}$ NPs). The wash durability of the nanocoating was also evaluated, confirming that the NPs were well attached to the fabrics and that the $\mathrm{SiO}_{2} \mathrm{NPs}$ improved this anchorage.

Ultimately, this work shows the development of a multifunctional fibrous system based on jute and $\mathrm{CaO}$ and $\mathrm{SiO}_{2} \mathrm{NPs}$, that can be used in several applications, having a specific potential for the application in personal protective equipment's, namely for protection against noxious chemical and biological agents, since the developed systems present the ability to degrade a toxic dye, which can possibly translate in the degradation of other harmful chemicals and present great antibacterial activity against gram-negative and gram-positive bacteria.

Acknowledgments The authors are thankful to project UID/ CTM/00264/2019 of 2C2T-Centro de Ciência e Tecnologia Têxtil, funded by National Founds through FCT/MCTESFundação para a Ciência e a Tecnologia, TSSiPRO project, operation code NORTE 01-0145-FEDER-000015, supported by the "Programa Operacional Regional do Norte" number NORTE-45-2015-02 and to the FCT PhD Scholarship (SFRH/ $\mathrm{BD} / 147812 / 2019$ ) of Joana Araújo. Diana Ferreira is thankful to CEECIND/02803/2017. Pilar Teixeira is also thankful to FCT, under the scope of the strategic funding of UIDB/04469/2020 unit and BioTecNorte operation (NORTE-01-0145-FEDER000004) funded by the European Regional Development Fund under the scope of Norte2020-Programa Operacional Regional do Norte.

Authors' contributions Joana C. Araújo was responsible for the experimental part and wrote the paper. Diana P. Ferreira supervised the work and also wrote the paper. Pilar Teixeira performed the antibacterial activity tests and participated in the writing of the paper. Raul Fangueiro also supervised the work.

\section{Compliance with ethical standards}

Conflict of interest The authors declare no conflict of interest.

\section{References}

Alavi M, Morsali A (2010) Ultrasonic-assisted synthesis of $\mathrm{Ca}(\mathrm{OH}) 2$ and $\mathrm{CaO}$ nanostructures. $\mathrm{J}$ Exp Nanosci 5:93-105. https://doi.org/10.1080/17458080903305616

Alzagameem A et al (2019) Antimicrobial activity of lignin and lignin-derived cellulose and chitosan composites against selected pathogenic and spoilage microorganisms. Polymers 11:670. https://doi.org/10.3390/polym11040670

Ameta R, Kumar D, Jhalora P (2014) Photocatalytic degradation of methylene blue using calcium oxide. Acta Chim Pharm Indica 4:20-28

Anantharaman A, Ramalakshmi S, George M (2016) Green synthesis of calcium oxide nanoparticles and its applications. Int J Eng Res Appl 6:27-31 
Anesh S, Mohamed A, Mohan K, Solaiappan A (2015) Enhanced near-infrared reflectance and functional characteristics of Al-doped $\mathrm{ZnO}$ nano-pigments embedded PMMA coatings. Sol Energy Mater Sol Cells 143:335-346. https://doi.org/10.1016/j.solmat.2015.07. 012

Badr Y, El-Wahed M, Mahmoud M (2008) Photocatalytic degradation of methyl red dye by silica nanoparticles. J Hazard Mater 154:245-253. https://doi.org/10.1016/j. jhazmat.2007.10.020

Balu S, Uma K, Pan G-T, Yang TC-K, Ramaraj SK (2018) Degradation of methylene blue dye in the presence of visible light using $\mathrm{SiO} 2 @ \alpha-\mathrm{Fe} 2 \mathrm{O} 3$ nanocomposites deposited on SnS2 flowers. Materials 11:1030. https://doi. org/10.3390/ma11061030

Bashari A, Shakeri M, Shirvan AR (2019) UV-protective textiles. In: The impact and prospects of green chemistry for textile technology. Woodhead Publishing, pp 327-365. https://doi.org/10.1016/B978-0-08-102491-1.00012-5

Becheri A, Dürr M, Lo Nostro P, Baglioni P (2008) Synthesis and characterization of zinc oxide nanoparticles: application to textiles as UV-absorbers. J Nanopart Res 10:679-689. https://doi.org/10.1007/s11051-007-9318-3

Bharathiraja DB, Sutha M, Krishnamoorthy S, Masi C, Dinakarkumar Y, Ramanujam PK (2018) Calcium oxide nanoparticles as an effective filtration aid for purification of vehicle gas exhaust. In: Advances in internal combustion engine research. Springer, Singapore, pp 181-192. https:// doi.org/10.1007/978-981-10-7575-9_9

Boufi S et al (2019) Cotton functionalized with nanostructured $\mathrm{TiO}_{2}-\mathrm{Ag}-\mathrm{AgBr}$ layer for solar photocatalytic degradation of dyes and toxic organophosphates. Int J Biol Macromol 128:902-910. https://doi.org/10.1016/j.ijbiomac.2019.01. 218

Cai Y, Ma S (2013) Progress in the study of antibacterial fibers. Adv Mater Res 821-822:103-106. https://doi.org/10.4028/ www.scientific.net/AMR.821-822.103

Chavali M, Nikolova M (2019) Metal oxide nanoparticles and their applications in nanotechnology. SN Appl Sci 1:607. https://doi.org/10.1007/s42452-019-0592-3

Costa SM, Ferreira DP, Ferreira A, Vaz F, Fangueiro R (2018) Multifunctional flax fibres based on the combined effect of silver and zinc oxide $(\mathrm{Ag} / \mathrm{ZnO})$ nanostructures. Nanomaterials 8:1069. https://doi.org/10.3390/nano8121069

del Río J et al (2009) Structural characterization of the lignin from jute (Corchorus capsularis) fibers. J Agric Food Chem 57:10271-10281. https://doi.org/10.1021/jf900815x

Duan W, Xie A, Shen Y, Wang X, Wang F, Zhang Y, Li J (2011) Fabrication of superhydrophobic cotton fabrics with UV protection based on $\mathrm{CeO}_{2}$ particles. Ind Eng Chem Res 50:4441-4445. https://doi.org/10.1021/ie101924v

El-Naggar M, Hassabo A, Mohamed A, Shaheen TI (2017) Surface modification of $\mathrm{SiO}_{2}$ coated $\mathrm{ZnO}$ nanoparticles for multifunctional cotton fabrics. J Colloid Interface Sci 498:413-422. https://doi.org/10.1016/j.jcis.2017.03.080

Ferreira DP, Conceição DS, Calhelha RC, Sousa T, Socoteanu R, Ferreira ICFR, Vieira Ferreira LF (2016) Porphyrin dye into biopolymeric chitosan films for localized photodynamic therapy of cancer. Carbohydr Polym 151:160-171. https://doi.org/10.1016/j.carbpol.2016.05.060
Ferreira DP, Ferreira A, Fangueiro R (2018) Searching for natural conductive fibrous structures via a green sustainable approach based on jute fibers and silver nanoparticles. Polymers 10:63. https://doi.org/10.3390/polym10010063

Galván-Ruiz M, Hernández J, Banos L, Noriega-Montes J, Rodríguez-García M (2009) Characterization of calcium carbonate, calcium oxide, and calcium hydroxide as starting point to the improvement of lime for their use in construction. J Mater Civ Eng 21:694-698. https://doi.org/10. 1061/(ASCE)0899-1561(2009)21:11(694)

Guan K (2005) Relationship between photocatalytic activity, hydrophilicity and self-cleaning effect of $\mathrm{TiO}_{2} / \mathrm{SiO}_{2}$ films. Surf Coat Technol 191:155-160. https://doi.org/10.1016/j. surfcoat.2004.02.022

Guna VK, Ilangovan M (2018) Curcuma longa L. plant residue as a source for natural cellulose fibers with antimicrobial activity. Ind Crops Prod 112:556-560. https://doi.org/10. 1016/j.indcrop.2017.12.042

Gunathilake C, Jaroniec M (2016) Mesoporous calcium oxidesilica and magnesium oxide-silica composites for $\mathrm{CO} 2$ capture at ambient and elevated temperatures. J Mater Chem A 4:10914-10924. https://doi.org/10.1039/ C6TA03916B

Hao L, Zheng T, Jiang J, Hu Q, Li X, Wang P (2015) Removal of As(III) from water using modified jute fibres as a hybrid adsorbent. RSC Adv 5:10723-10732. https://doi.org/10. 1039/C4RA11901K

Ilangovan M, Guna V, Prajwal B, Jiang Q, Reddy N (2020) Extraction and characterisation of natural cellulose fibers from Kigelia africana. Carbohyd Polym 236:115996. https://doi.org/10.1016/j.carbpol.2020.115996

Ivanovska A, Cerovic D, Maletic S, Castvan I, Asanovic K, Kostic M (2019) Influence of the alkali treatment on the sorption and dielectric properties of woven jute fabric. Cellulose 26:5133-5146. https://doi.org/10.1007/s10570019-02421-0

Jhatial A, Khatri A, Ali S, Babar A (2019) Sol-gel finishing of bamboo fabric with nanoparticles for water repellency, soil release and UV resistant characteristics. Cellulose 26:6365-6378. https://doi.org/10.1007/s10570-01902537-3

Joshi M, Adak B (2018) Advances in nanotechnology based functional, smart and intelligent textiles: a review. In: Comprehensive nanoscience and nanotechnology, 2nd edn. Academic Press, pp 253-290. https://doi.org/10.1016/ B978-0-12-803581-8.10471-0

Kornprobst T, Plank J (2012) Photodegradation of Rhodamine B in presence of $\mathrm{CaO}$ and $\mathrm{NiO}-\mathrm{CaO}$ catalysts. Int $\mathrm{J}$ Photoenergy 2012:6. https://doi.org/10.1155/2012/398230

Li K, Jianguo J, Tian S, Chen X, Yan F (2014) Influence of silica types on synthesis and performance of amine-silica hybrid materials used for $\mathrm{CO}_{2}$ capture. $\mathrm{J}$ Phys Chem $\mathrm{C}$ 118:2454-2462. https://doi.org/10.1021/jp408354r

Marmur A, Volpe C, Siboni S, Amirfazli A, Drelich J (2017) Contact angles and wettability: towards common and accurate terminology. Surf Innov 5:1-24. https://doi.org/ 10.1680/jsuin.17.00002

Mary Ealias A, Saravanakumar MP (2017) A review on the classification, characterisation, synthesis of nanoparticles and their application. IOP Conf Ser Mater Sci Eng 
263:032019. https://doi.org/10.1088/1757-899X/263/3/ 032019

Nagpal M, Kakkar R (2019) Use of metal oxides for the adsorptive removal of toxic organic pollutants. Sep Purif Technol 211:522-539. https://doi.org/10.1016/j.seppur. 2018.10.016

Nallathambi G (2011) Effect of silica nanoparticles and BTCA on physical properties of cotton fabrics. J Mater Res 14:552-559. https://doi.org/10.1590/S151614392011005000086

Nguyen N, Padil V, Slaveykova VI, Cernik M, Ševců A (2018) Green synthesis of metal and metal oxide nanoparticles and their effect on the unicellular alga Chlamydomonas reinhardtii. Nanoscale Res Lett 13:1-13. https://doi.org/10. 1186/s11671-018-2575-5

Peerzada J, Mulay P, Venkat R, Chidambaram R (2019) Multifaceted application of silica nanoparticles. A review. Silicon. https://doi.org/10.1007/s12633-019-00229-y

Qiu Q et al (2020) Functional nanofibers embedded into textiles for durable antibacterial properties. Chem Eng J 384:123241. https://doi.org/10.1016/j.cej.2019.123241

Ren G, Hu D, Cheng E, Vargas-Reus M, Reip P, Allaker R (2009) Characterisation of copper oxide nanoparticles for antimicrobial applications. Int $\mathrm{J}$ Antimicrob Agents 33:587-590. https://doi.org/10.1016/j.ijantimicag.2008. 12.004

Roe B, Zhang X (2009) Durable hydrophobic textile fabric finishing using silica nanoparticles and mixed silanes. Text Res J 79:1115-1122. https://doi.org/10.1177/ 0040517508100184

Roy A, Gauri DS, Bhattacharya M, Bhattacharya J (2013) Antimicrobial activity of $\mathrm{CaO}$ nanoparticles. J Biomed Nanotechnol 9:1570-1578. https://doi.org/10.1166/jbn. 2013.1681

Sahu U, Mahapatra S, Patel R (2017) Synthesis and characterization of an eco-friendly composite of jute fiber and $\mathrm{Fe} 2 \mathrm{O} 3$ nanoparticles and its application as an adsorbent for removal of $\mathrm{As}(\mathrm{V})$ from water. J Mol Liq 237:313-321. https://doi.org/10.1016/j.molliq.2017.04.092

Sasani Ghamsari M, Alamdari S, Han W, Park HH (2017) Impact of nanostructured thin $\mathrm{ZnO}$ film in ultraviolet protection. Int J Nanomed 12:207-216. https://doi.org/10. 2147/IJN.S118637
Seyfi J, Hejazi I, Jafari SH, Khonakdar H, Simon F (2016) Enhanced hydrophobicity of polyurethane via non-solvent induced surface aggregation of silica nanoparticles. J Colloid Interface Sci 478:117-126. https://doi.org/10.1016/j. jcis.2016.06.005

Silva I, Bevitori A, Rohen L, Margem F, de Oliveira Braga F, Monteiro S (2016) Characterization by Fourier transform infrared (FTIR) analysis for natural jute fiber. Mater Sci Forum 869:283-287. https://doi.org/10.4028/www. scientific.net/MSF.869.283

Sümengen Özdenefe M, Muhammed A, Süer K, Güler E, Mercimek Takci HA (2019) Determination of antimicrobial activity of corchorus olitorius leaf extracts. Cyprus J Med Sci 3:159-163. https://doi.org/10.5152/cjms.2018. 623

Tangboriboon N, Kunanuruksapong R, Sirivat A (2012) Preparation and properties of calcium oxide from eggshells via calcination. Mater Sci Pol 30:313-322. https://doi.org/ 10.2478/s13536-012-0055-7

Tissera ND, Wijesena RN, Perera JR, de Silva KMN, Amaratunge GAJ (2015) Hydrophobic cotton textile surfaces using an amphiphilic graphene oxide (GO) coating. Appl Surf Sci 324:455-463. https://doi.org/10.1016/j.apsusc. 2014.10.148

Veeran K, Lakshamaiah M, Narayan R (2014) Photocatalytic degradation of indigo carmine dye using calcium oxide. Int J Photochem 2014:6. https://doi.org/10.1155/2014/530570

Yang L, Kruse B (2004) Revised Kubelka-Munk Theory I. Theory and application. J Opt Soc Am A 21:1933-1941. https://doi.org/10.1364/JOSAA.21.001933

Yang C et al (2017) Highly efficient photocatalytic degradation of methylene blue by P2ABSA-modified TiO 2 nanocomposite due to the photosensitization synergetic effect of TiO 2 and P2ABSA. RSC Adv 7:23699-23708. https://doi.org/10.1039/C7RA02423A

Zouheyr B, Ati A, Mansour R (2015) Characterization of new natural cellulosic fiber from Lygeum Spartum L. Carbohyd Polym 134:429-437. https://doi.org/10.1016/j.carbpol. 2015.08.024

Publisher's Note Springer Nature remains neutral with regard to jurisdictional claims in published maps and institutional affiliations. 